\title{
Comparision of Low-Cost and Eco-Friendly Adsorbent for Adsorption of $\mathrm{Ni}(\mathrm{II})$
}

\author{
Muharrem Ince \\ Faculty of Engineering, Department of Chemical Engineering, \\ Tunceli University, Tunceli, Turkey
}

\section{INTRODUCTION}

Arsenic (As), cadmium (Cd), chromium (Cr), cobalt (Co), copper $(\mathrm{Cu})$, lead $(\mathrm{Pb})$, mercury $(\mathrm{Hg})$, and nickel (Ni) are heavy metals and of great concern. They are not biodegradable, tend to accumulate in living organisms, and cause various diseases and disorders (1). Chemical precipitation, ion exchange, solvent extraction, reverse osmosis, and adsorption are some of the methods used for removal of these and other metals. The process of adsorption has become one of the preferred methods for removal of toxic contaminants because the adsorption method is very effective, economical, versatile, and simple. Additional advantages are its applicability at very low concentrations, suitability for using batch and continuous processes, ease of operation, little sludge generation, and the possibility of regeneration and reuse (2). Different solid phases have been used as solid-phase extractants for enrichment of trace metal ions (3). In the past two decades, researchers have mostly been using low-cost effective adsorbents for heavy metal adsorption, and the sorption behavior of several natural waste materials have also been investigated (1). Numerous adsorbents, obtained from natural wastes have been used for the removal of aluminum, nickel, cadmium, chromium, copper, iron, lead, and zinc and include the leaf, stem, and root phytomass of holly oak (4), CACMM2 powder extracted from a cactus (5), starch, activated charcoal, wood charcoal, and clay (6), groundnut husks (7), bark (8-10),

\footnotetext{
Corresponding autbor.

E-mail: mubarremince@tunceli.edu.tr
}

\begin{abstract}
In this study, samples of clay, tea waste, astragalus plant, chestnut shell, and egg shell were used as low-cost and eco-friendly adsorbents for the adsorption of $\mathrm{Ni}$ (II) from aqueous solutions. The effect of various parameters such as $\mathrm{pH}$, contact time, adsorbent dose, and final volume on the adsorption capacities of these natural adsorbents were investigated by batch experiments. The adsorption capacity for $\mathrm{Ni}$ (II) was found to be $19.4 \mathrm{mg} \mathrm{g}^{-1}, 5.4 \mathrm{mg} \mathrm{g}^{-1}$, $1.3 \mathrm{mg} \mathrm{g}^{-1}, 5.6 \mathrm{mg} \mathrm{g}^{-1}, 72.0 \mathrm{mg} \mathrm{g}^{-1}$ for clay, tea waste, astragalus plant, chestnut shell, and egg shell, respectively. Egg shell has maximum adsorption capacity at pH 12, 45-minute contact time, and $0.5 \mathrm{~g}$ adsorbent mass. Nickelfree and nickel-loaded adsorbents were characterized by FTIR spectroscopy, which evidenced the functional groups involved in nickel uptake. This work investigated the utilization of ecofriendly and low-cost adsorbents as an alternative natural adsorbent for $\mathrm{Ni}(\mathrm{II})$ ions.
\end{abstract}

sunflower stalks (11), bagasse (12), rice husk (13) and sawdust $(14,15)$.

Atomic spectrometry techniques are generally used for the quantification of metals. Flame atomic absorption spectrometry (FAAS) has advantages such as low cost, good selectivity, and high analytical frequency. However, the direct determination of trace metals by this technique can be difficult because of the low concentration of these metals in the samples (16). Sample solutions with low concentrations require a preconcentration method. Solid phase extraction is a simple and eco-friendly procedure with a high preconcentration factor (17). Column or batch techniques can be used for solid phase extraction. In the batch technique, aqueous samples are added to a suitable vessel containing a sorbent and stirred for a known period of time to attain the sorption equilibrium as quickly as possible. Then the solid phase is separated from the solution by filtration or decantation and the metal ions retained on the sorbent are eluted with a small volume of organic or inorganic solvent. Metals ions are determined in the elution solution by an appropriate analytical technique such as atomic absorption, atomic emission, or mass spectrometry (18). The obvious advantage of the adsorption method is the low costs involved. Hence, there is a need to search for more economical and effective sorbents (19). The objective of this study was to investigate the possibility of using eco-friendly and low cost materials such as clay, tea waste, astragalus plant, chestnut shell, and egg shell, and to compare and evaluate the adsorption capacities of these adsorbents for $\mathrm{Ni}$ (II) determination.

\section{EXPERIMENTAL}

\section{Chemicals}

Analytical grade nickel chloride, sodium hydroxide, hydrochloric acid, sodium citrate monohydrate, sodium dihydrogen phosphate, sodium tetraborate, glycine and nitric acid were used (Merck, Darmstadt, Germany).

\section{Preparation of Natural Adsor- bents: Egg Shell, Chestnut, Black Tea, Clay, and Astragalus \\ The egg shells were washed with distilled water, then calcined in an ashing oven at $900{ }^{\circ} \mathrm{C}$ for eight hours. The calcined egg shells}


were ground in a blender and sifted through a $<120$ mesh sieve.

The chestnuts were purchased at a local market and washed with distilled water to remove any dirt. The samples were cooked on a portable electric heating element, then the skin was peeled off.

The black tea samples were steeped and the residue washed with hot distilled water until the water became colorless. The black tea waste was dried in oven at $60{ }^{\circ} \mathrm{C}$ until constant weight.

The clay sample was crushed and milled, washed with distilled water and dried in an oven at $60{ }^{\circ} \mathrm{C}$ until constant weight.

The Astragalus plant samples were picked at Tunceli, washed with tap water, then with distilled water. After washing, the samples were dried in an oven at $60^{\circ} \mathrm{C}$ until constant weight.

All of the dried adsorbents were ground in a blender, sieved to a particle size of $<120 \mathrm{mesh}$, and stored in polyethylene bags at room temperature until use.

\section{Adsorption Studies}

\section{Instrumentation}

In this investigation, batch adsorption experiments were performed to determine the adsorption capacities of the chestnut shell, tea waste, astragalus, clay, and egg shell. Batch experiments were carried out at room temperature $\left(25 \pm 1{ }^{\circ} \mathrm{C}\right)$ using a magnetic stirrer (Daihan Scientific, MSH-20A, SeoulKorea) in a Pyrex ${ }^{\circledR}$ beaker covered with stretch film to prevent contamination. The batch adsorption experiments were carried out by shaking a known amount of the natural adsorbent at various $\mathrm{pH}$ values, stirring times, adsorbent amounts, and final volumes for the determination of $\mathrm{Ni}$ (II) at optimum conditions. The final solutions were filtered through a Macherey-Nagel
640 de $110-\mathrm{mm}$ filter paper (Macherey-Nagel, Düren, Germany), and the remaining Ni concentrations were determined using a PerkinElmer ${ }^{\circledR}$ AAnalyst ${ }^{\mathrm{TM}} 800$ flame atomic absorption spectrometer (FAAS) (PerkinElmer, Inc., Shelton, CT, USA). The instrumental operating conditions are listed in Table I.

All experiments were performed in triplicate and the results given here are the average of these measurements. Blank experiments were processed without addition of adsorbents. For the pH adjustments, $0.1 \mathrm{M}$ hydrochloric acid and sodium hydroxide were used. A digital Jenco 6173 pH meter (Shanghai Jenco Electronics, Shanghai, China) was used for the pH measurements.

\section{Characterization of Adsorbents}

FTIR Spectra for Comparison

Fourier transform infrared (FTIR) spectra of all of the the pretreated samples were compared to the FTIR spectra of nickel-loaded clay, tea waste, astragalus plant, chestnut shell, and egg shell. The spectra were recorded in the frequency range of $4000-500 \mathrm{~cm}^{-1}$ using an FTIR spectrophotometer (Thermo Scientific, USA). The samples were crushed and prepared with $\mathrm{KBr}$ forming pellets.

\section{RESULTS AND DISCUSSION}

\section{Effect of pH}

For $\mathrm{pH}$ optimization, $0.25 \mathrm{~g}$ of each adsorbent was weighed with a Radwag AS 220/C/2 analytical balance (Radwag Balances \& Scales, Poland) and mixed with $50 \mathrm{~mL}$ of aqueous $\mathrm{Ni}(\mathrm{II})$ solution as follows: astragalus plant, tea waste, chestnut shell with $15.0 \mathrm{mg} \mathrm{L}^{-1}$, clay adsorbent with $100 \mathrm{mg} \mathrm{L}^{-1}$, and egg shell with $360 \mathrm{mg} \mathrm{L}^{-1}$, and then placed in a magnetic stirrer (10-180 minutes). The $\mathrm{pH}$ was optimized for citrate from 2-5, phosphate from 6-7,
TABLE I

Instrumental Operating Conditions of AAnalyst 800 FAAS

\begin{tabular}{ll}
\hline Parameters & Values \\
\hline Wavelength & $232 \mathrm{~nm}$ \\
HCL current & $20.0 \mathrm{~mA}$ \\
Flow rates: & \\
Air & $17 \mathrm{~L} / \mathrm{min}$ \\
Acetylene & $2 \mathrm{~L} / \mathrm{min}$ \\
Slit width & $0.2 \underline{\mathrm{nm}}$ \\
\hline
\end{tabular}

borate from 8-10, and glycine buffers from 11-13. It was observed that adsorption of $\mathrm{Ni}$ (II) was maximum for clay at $\mathrm{pH} 10$, tea waste at $\mathrm{pH}$ 9, astragalus plant at $\mathrm{pH} 7$, chestnut shell at $\mathrm{pH} 7$, and egg shell at $\mathrm{pH} 12$. The results are shown in Figure 1 ( $a$ and $b$ ). The correlation between the metal uptake and $\mathrm{pH}$ is related to the acid-base properties of the various functional groups on the adsorbent surfaces, mainly the carboxyl groups (20). The increase in both the metal adsorption and the $\mathrm{pH}$ values can be explained as the competition between the proton and nickel ions for the same functional groups and by a decrease in the positive surface charges which results in a higher electrostatic attraction between the surface and the metal (20).

Carvalho et al. (21) obtained different results for clay and tea waste and used the silylated clays to remove $\mathrm{Ni}$ (II) from the aqueous effluents. They determined that the maximum value of metal retention occurred at a $\mathrm{pH}$ of about 6.0 , and that there was a decrease in the capacity of retention in solutions with a reduced $\mathrm{pH}$ (21). In an another study, tea waste was used as the adsorbent and maximum adsorption of the $\mathrm{Ni}(\mathrm{II})$ ions was observed at $\mathrm{pH} 4.0$ (22). Jiang et al. (23) found that the adsorption of $\mathrm{Ni}(\mathrm{II})$ increased in kaolinite clay with a $\mathrm{pH}$ from 2.0 to 8.0. When the $\mathrm{pH}$ increased from 7 to 12 , 


\section{Atomic Apectroscopy \\ $\bigcirc$ Vol. 35(5), Sept./Oct. 2014}

a significant increase in adsorption (about 6-fold) was observed for egg shell, while for clay it was about 4-fold. There was no big change due to the other parameters such as stirring time, final volume, and adsorbent amount.

\section{Effect of Stirring Time}

The influence of contact time on the adsorption of $\mathrm{Ni}$ (II) on tea waste, astragalus plant, chestnut shell, and egg shell was evaluated from 10-180 minutes (Figure 2 a and b). The contact time was fixed at 45 minutes for clay, tea waste, and egg shell, at 60 minutes for astragalus plant, and at 90 minutes for chestnut shell. Gupta et al. (24) used waste rubber tire as the adsorbent. In that study, the adsorption efficiency increased to 120 minutes of contact time after which the capacity levelled off. Therefore, they selected 120 minutes as the optimum contact time (24). In the study by Jiang et al., the initial adsorption was found to be very fast with maximum uptake within 30 minutes for $\mathrm{Ni}(\mathrm{II})$ (23).

\section{Effect of Final Volume}

The final volume of the Ni solution was studied in addition to the other optimum conditions in order to determine the amount of volume for optimum adsorption. For this purpose, the adsorbents were interacted with $\mathrm{Ni}(\mathrm{II})$ solutions which were at the same concentrations (for clay $100 \mathrm{mg} \mathrm{L}^{-1}$, for egg shell $360 \mathrm{mg} \mathrm{L}^{-1}$, for astragalus plant, tea waste and chestnut shell $15 \mathrm{mg} \mathrm{L}^{-1}$ ) but at different volume (25-400 $\mathrm{mL}$ ). Figure 3 shows the optimum final volume used for $\mathrm{Ni}$ (II) adsorption. According to the obtained results, the solution volume has little effect on the adsorption capacity of the adsorbents. The adsorption capacities were about the same regardless of the volume amount. The final volume selected was $50 \mathrm{~mL}$ each for clay, astragalus plant and egg shell, and $100 \mathrm{~mL}$ each for tea waste and chestnut shell.

\section{Effect of Adsorbent Amount}

The adsorption of nickel ions on clay, tea waste, astragalus plant, chestnut shell, and egg shell was studied on amounts ranging from 0.1 to $1.0 \mathrm{~g}$ in a $50-\mathrm{mL}$ solution volume with a specific stirring time and $\mathrm{pH}$. The adsorbed $\mathrm{Ni}$ amount increased with an increase in the adsorbent from $0.1 \mathrm{~g}$ to $0.25 \mathrm{~g}$, and decreased after $0.25 \mathrm{~g}$ of adsorbent for clay and the astragalus plant. The adsorbed Ni amount increased with an increase in the adsorbent from $0.1 \mathrm{~g}$ to $0.5 \mathrm{~g}$ and decreased after $0.5 \mathrm{~g}$ of adsorbent for tea waste, egg shell, and chestnut shell. Therefore, $0.25 \mathrm{~g}$ each of clay and astragalus and $0.5 \mathrm{~g}$ each of tea waste, egg shell, and chestnut shell were selected as the adsorbent mass. The adsorption efficiency of
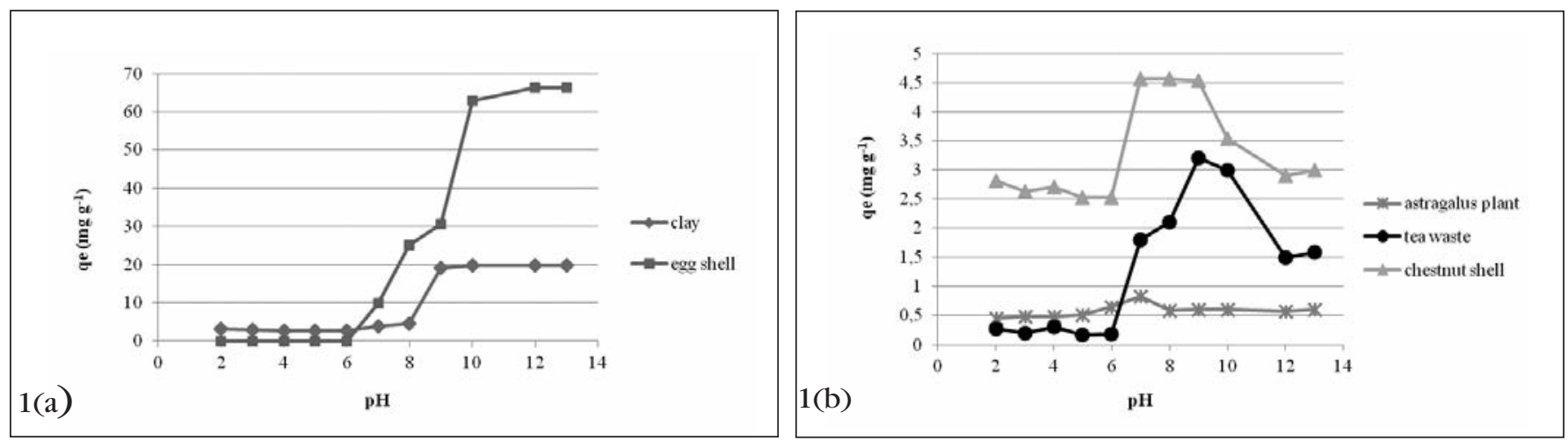

Fig. 1 ( $a$ and $b$ ). Effect of pH on adsorption capacity of nickel on (a) and $\mathbf{\Delta}$ chestnut shell.
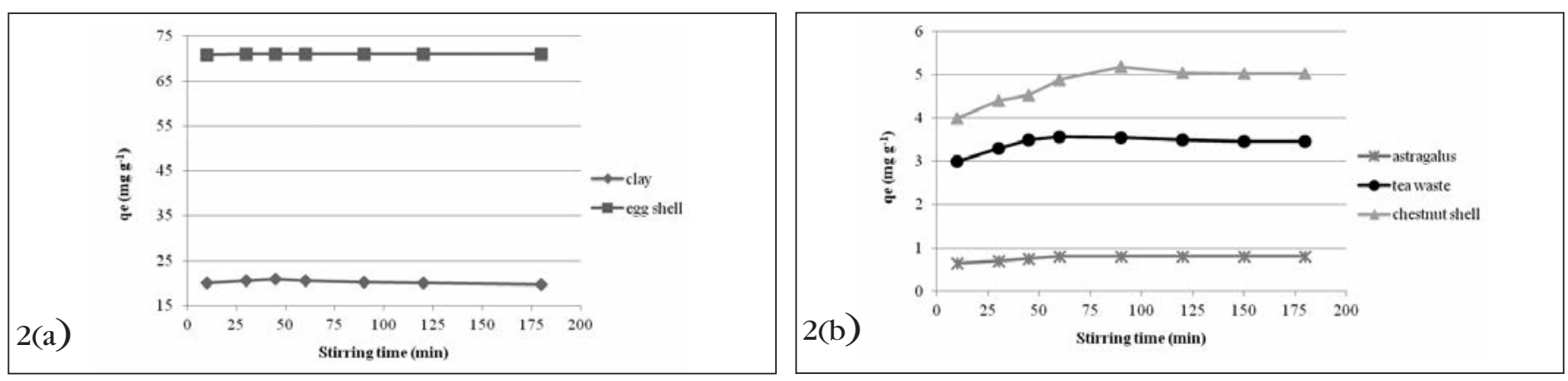

Fig. 2 ( $a$ and b). Effect of stirring time on adsorption capacity of nickel on (a) $\$ clay and $\mathbf{\square}$ egg shell; (b) $*$ astragalus plant, tea waste, and $\mathbf{\Delta}$ chestnut shell. 
$\mathrm{Ni}(\mathrm{II})$ as a function of adsorbent amount is shown in Figure 4.

The decrease in $\mathrm{q}_{\mathrm{e}}$ with an increase in the adsorbent amount is mainly due to the unsaturation of the adsorption sites through the adsorption reaction. Another reason may be due to the particle interactions, such as aggregation, resulting from high sorbent concentrations. Such aggregation would lead to a decrease in the total surface area of the adsorbent (25).

Choksi and Joshi (26) investigated the removal of $\mathrm{Ni}(\mathrm{II})$ from wastewater using natural adsorbents such as starch, activated charcoal, wood charcoal, and clay. For clay, they determined that the amount adsorbed increased from 0.09 to $0.099 \mathrm{~g}$ per $0.25 \mathrm{~g}$ of adsorbent with an increase in $\mathrm{pH}$ from 6 to 8.5 , respectively. For clay, the amount adsorbed increased from $0.098 \mathrm{~g}$ per $0.2 \mathrm{~g}$ to $0.099 \mathrm{~g}$ per
$1.0 \mathrm{~g}$ at $30^{\circ} \mathrm{C}$, at $\mathrm{pH} 7.5$ for $\mathrm{Ni}(\mathrm{II})$.

\section{Ni(II) Adsorption Capacities of Natural Adsorbents}

The amount of $\mathrm{Ni}(\mathrm{II})$ adsorption was calculated according to the following equation:

$$
\left.\mathrm{q}_{\mathrm{e}}=\left(\mathrm{C}_{0}-\mathrm{C}_{\mathrm{e}}\right) \times \mathrm{V}\right) / \mathrm{m} \quad \text { Eq. } 1
$$

where $\mathrm{q}_{\mathrm{e}}$ is the amount ( $\mathrm{mg} \mathrm{g}^{-1}$ ) of $\mathrm{Ni}(\mathrm{II})$ adsorbed by the clay, tea waste, astragalus plant, chestnut shell, and egg shell adsorbents. $\mathrm{C}_{0}$ and $\mathrm{C}_{\mathrm{e}}$ are the metal concentrations ( $\left.\mathrm{mg} \mathrm{L}^{-1}\right)$ in the solution initially and after adsorption, respectively. $\mathrm{V}$ is the volume $(\mathrm{L})$ of the solution and $\mathrm{m}$ is the mass (g) of adsorbent used.

The adsorption percentage was calculated according to the following equation:

$\mathrm{A} \%=$ (Amount of adsorbed metal ions/amount of initial metal ions) $\times 100$

Eq. 2 where $\mathrm{Ni}$ (II) adsorption capacities of the natural adsorbents were calculated at optimum conditions for each other. The $\mathrm{q}_{\mathrm{e}}$ values found were $19.42 \mathrm{mg} \mathrm{g}^{-1}, 5.44 \mathrm{mg} \mathrm{g}^{-1}$, $1.3 \mathrm{mg} \mathrm{g}^{-1}, 5.6 \mathrm{mg} \mathrm{g}^{-1}$, and $72 \mathrm{mg} \mathrm{g}^{-1}$ for clay, tea waste, astragalus plant, chestnut shell, and egg shell, respectively. According to the obtained results, egg shell has maximum absorption capacity when compared to the other natural eco-friendly adsorbents of this study, and the adsorption capacity of clay was approximately the same. The adsorption percentages were determined as $97.0 \%, 36.3 \%$, $8.7 \%, 37.3 \%$, and $99.8 \%$ for clay, tea waste, astragalus plant, chestnut shell, and egg shell, respectively.

\section{FTIR Analysis of Adsorbents}

The spectra of the adsorbents were measured using a Thermo Nicolet Is10 FT-IR (Thermo Scientific, USA) for the determination of
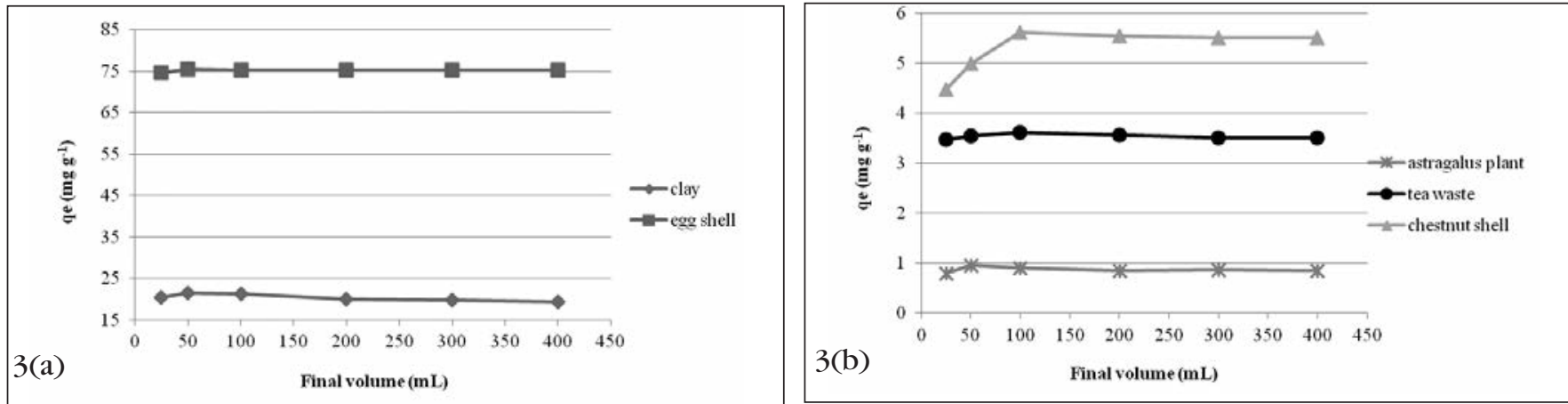

Fig. 3 ( $a$ and b). Effect of final volume on adsorption capacity of nickel on (a) $>$ clay and $\mathbf{\square}$ egg shell; (b) * astragalus plant, tea waste, and $\mathbf{\Delta}$ chestnut shell.
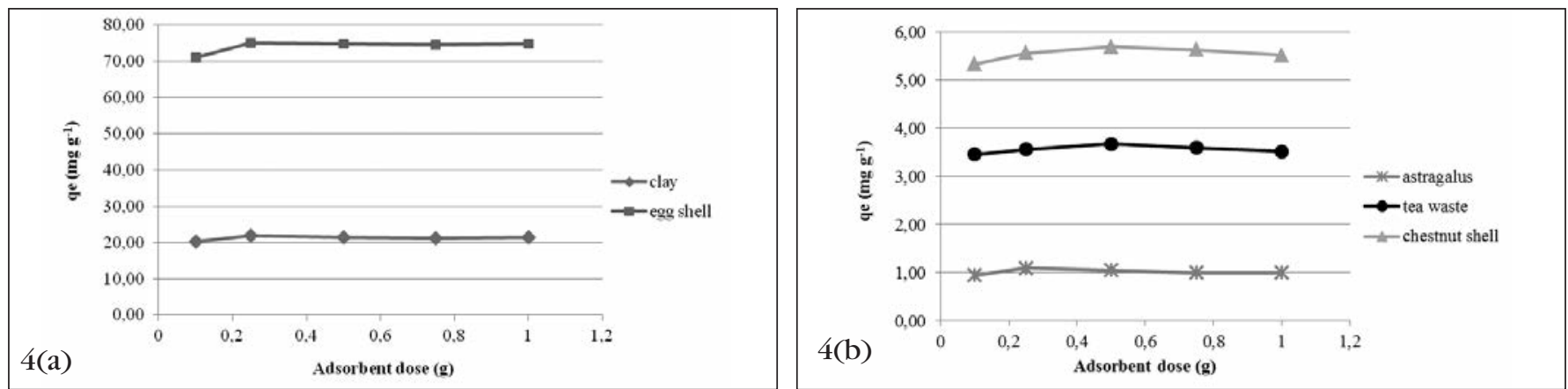

Fig. 4 ( $a$ and b). Effect of adsorbent dose on adsorption capacity of nickel on (a) $\downarrow$ clay and $\mathbf{\square}$ egg shell; (b) * astragalus plant, $\bigcirc$ tea waste, and $\mathbf{\Delta}$ chestnut shell. 


\section{A $_{\text {Spectroscopy }}^{\text {pectros }}$ \\ 1 Vol. 35(5), Sept./Oct. 2014}

the vibrational frequency changes in the functional groups of the adsorbents before and after adsorption of nickel. The FTIR instrumental operating conditions are listed in Table II. Figures 5-9 ( $a$ and b) show the peaks of the different adsorbents before and after use.

The adsorption band at approximately $3300 \mathrm{~cm}^{-1}$ is attributable to the hydroxyl groups from the polyphenols originally present in the chestnut shell, tea waste, and astragalus plant (Figure 7-9). The peaks observed at $2900 \mathrm{~cm}^{-1}$ can be assigned to stretching vibrations of the C-H groups for the chestnut shell, tea waste, and astragalus plant (Figure 7-9) (27). The observed band around $2851 \mathrm{~cm}^{-1}$ was assigned to the stretching vibration of the $\mathrm{C}-\mathrm{H}$ alkane groups for tea waste (28). The band around $1730 \mathrm{~cm}^{-1}$ is due to a $\mathrm{C}=\mathrm{O}$ group of carboxylic acid or its ester for chestnut shell and tea waste (29). The peak around $1620 \mathrm{~cm}^{-1}$ is due to the $\mathrm{C}=\mathrm{C}$ aromatic or may be the asymmetric and symmetric stretching $\mathrm{C}=\mathrm{O}$ vibration for tea waste (30). The observed band at $1236 \mathrm{~cm}^{-1}$ is due to the $-\mathrm{SO}_{3}$ stretching for chestnut shell, tea waste, and the astragalus plant (29). The bands at 3639-3617 $\mathrm{cm}^{-1}$ for clay and egg shell (Figure 5-6) can be attributed to the hydroxyl groups on the surface material (31). The band at $3407 \mathrm{~cm}^{-1}$ can be attributed to the presence of the $\mathrm{O}-\mathrm{H}$ and $\mathrm{N}-\mathrm{H}$ groups, while the band at $1634 \mathrm{~cm}^{-1}$ reflects the carbonyl group stretching (amide) for clay. The band around $1456 \mathrm{~cm}^{-1}$ for clay and egg shell is attributed to the symmetric bending of $\mathrm{CH}_{3}$. All of these functions are likely to participate in $\mathrm{Ni}^{2+}$ binding to these adsorbents. The shifts and intensity changes of the FTIR bands observed were rather weak, which can be an indication of the dominance of ion exchange over the precipitation/ coprecipitation
TABLE II

Instrumental Parameters for FTIR Analysis

\begin{tabular}{lr}
\hline Wavelength range $\quad 4000-500 \mathrm{~cm}^{-1}$ \\
Sample to $\mathrm{KBr}$ mass ratio & $1: 100$ \\
Spectral resolution & $4 \mathrm{~cm}^{-1}$ \\
\hline
\end{tabular}

occurring during $\mathrm{Ni}^{2+}$ sorption on these sorbents (29).

\section{CONCLUSION}

In the present study, a batch technique for the adsorption of $\mathrm{Ni}(\mathrm{II})$ has been carried out using clay, tea waste, astragalus plant, chestnut shell, and egg shell as adsorbents and basic procedures are provided for their use. The important parameters for the batch technique such as $\mathrm{pH}$, contact time, adsorbent dose, and final volume were studied for determining their adsorption capacities. It was found that clay and especially egg shell are good adsorbents for Ni(II), and the adsorption percentages are very high. Most of these adsorbents are waste materials, except for clay and the astragalus plant, and all can easily be obtained, are eco-friendly, and low cost.

\section{ACKNOWLEDGMENT}

This study was part of a project, entitled "Determination of Metal Retention Capacity of Some Natural Adsorbents and Its Application to Various Water Samples," supported by the Tunceli University Scientific Investigations Project Unit (TUNIBAP-MFTUB012-08).

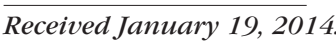



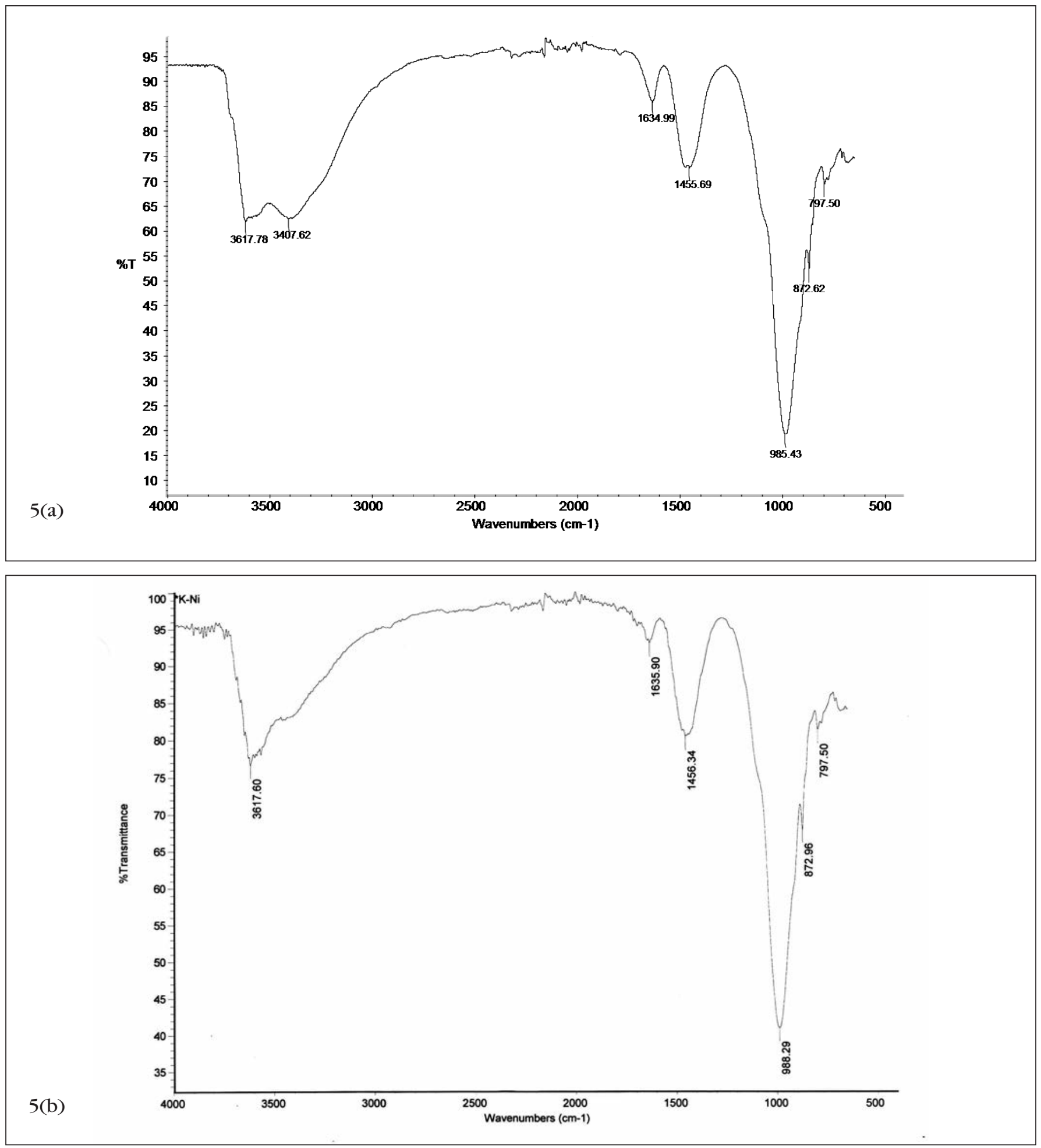

Fig. 5 ( $a$ and b). FTIR spectra of (a) clay and (b) Ni-loaded clay. 


\section{A Spectroscopy $^{\text {tomic }}$ \\ $\circlearrowleft$ Vol. 35(5), Sept./Oct. 2014}

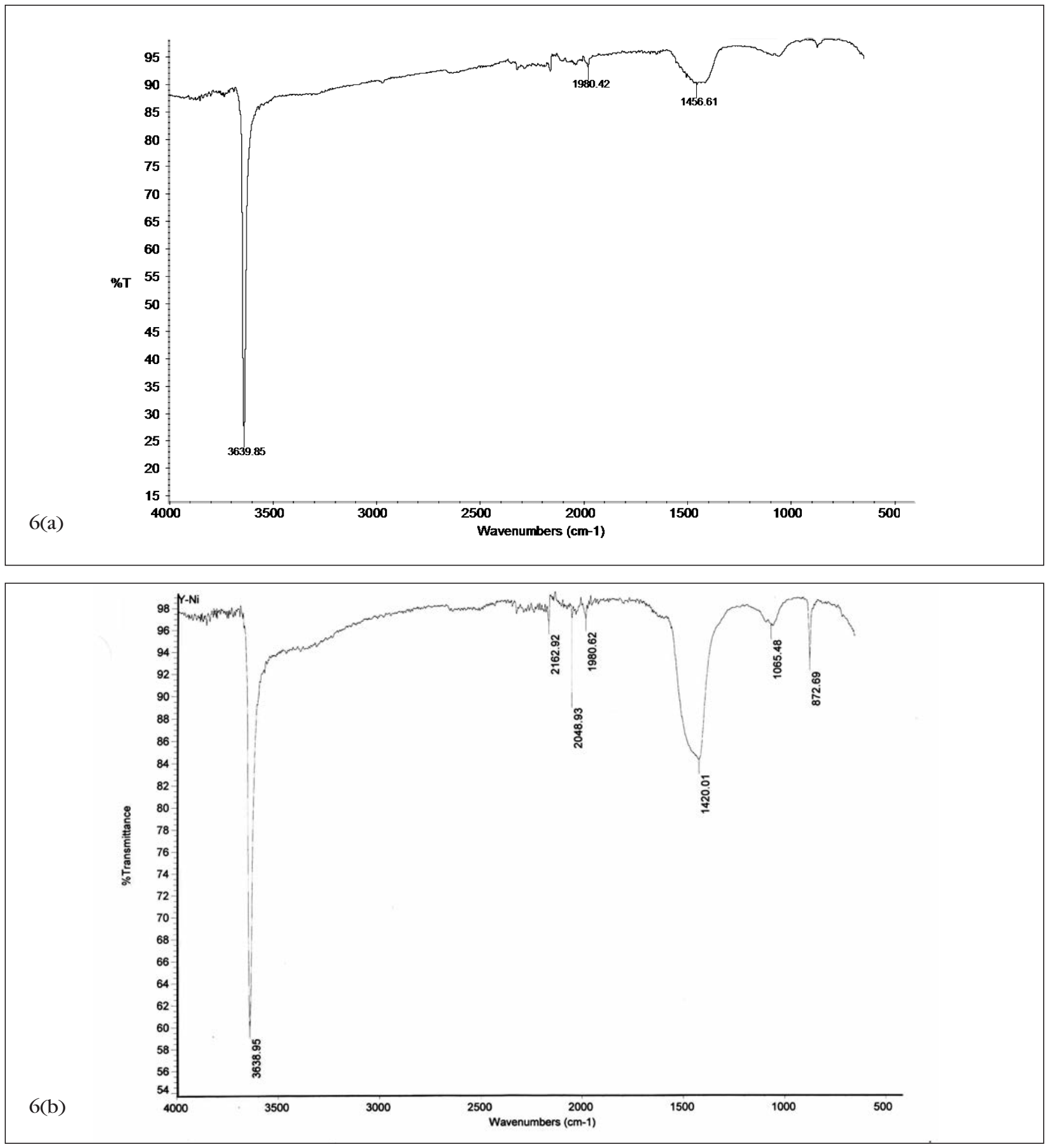

Fig. 6 ( $a$ and b). FTIR spectra of (a) egg shell and (b) Ni loaded egg shell. 

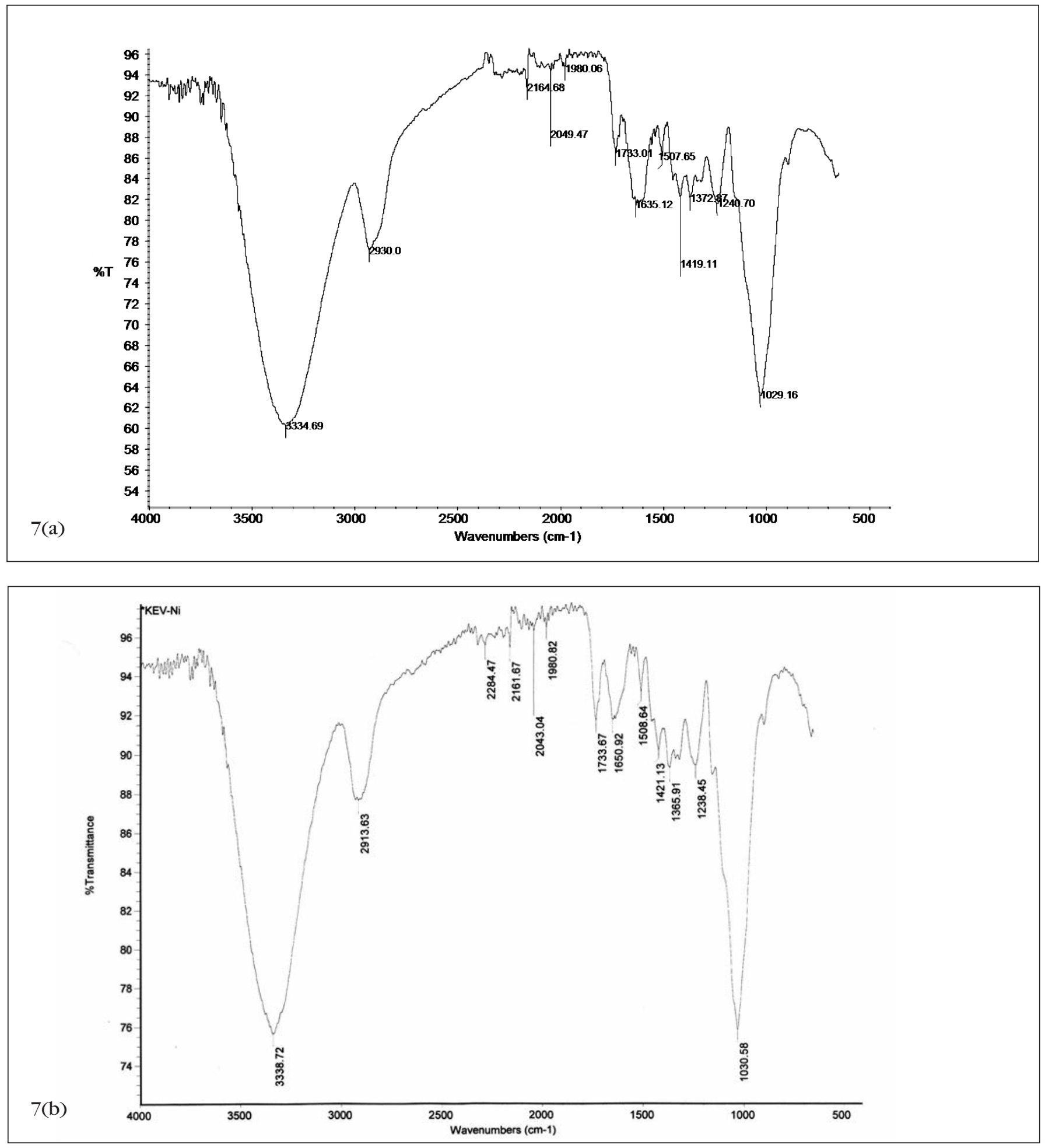

Fig. 7 ( $a$ and b). FTIR spectra of (a) astragalus and (b) Ni-loaded astragalus. 


\section{Atomic \\ $\checkmark$ Vol. 35(5), Sept./Oct. 2014}
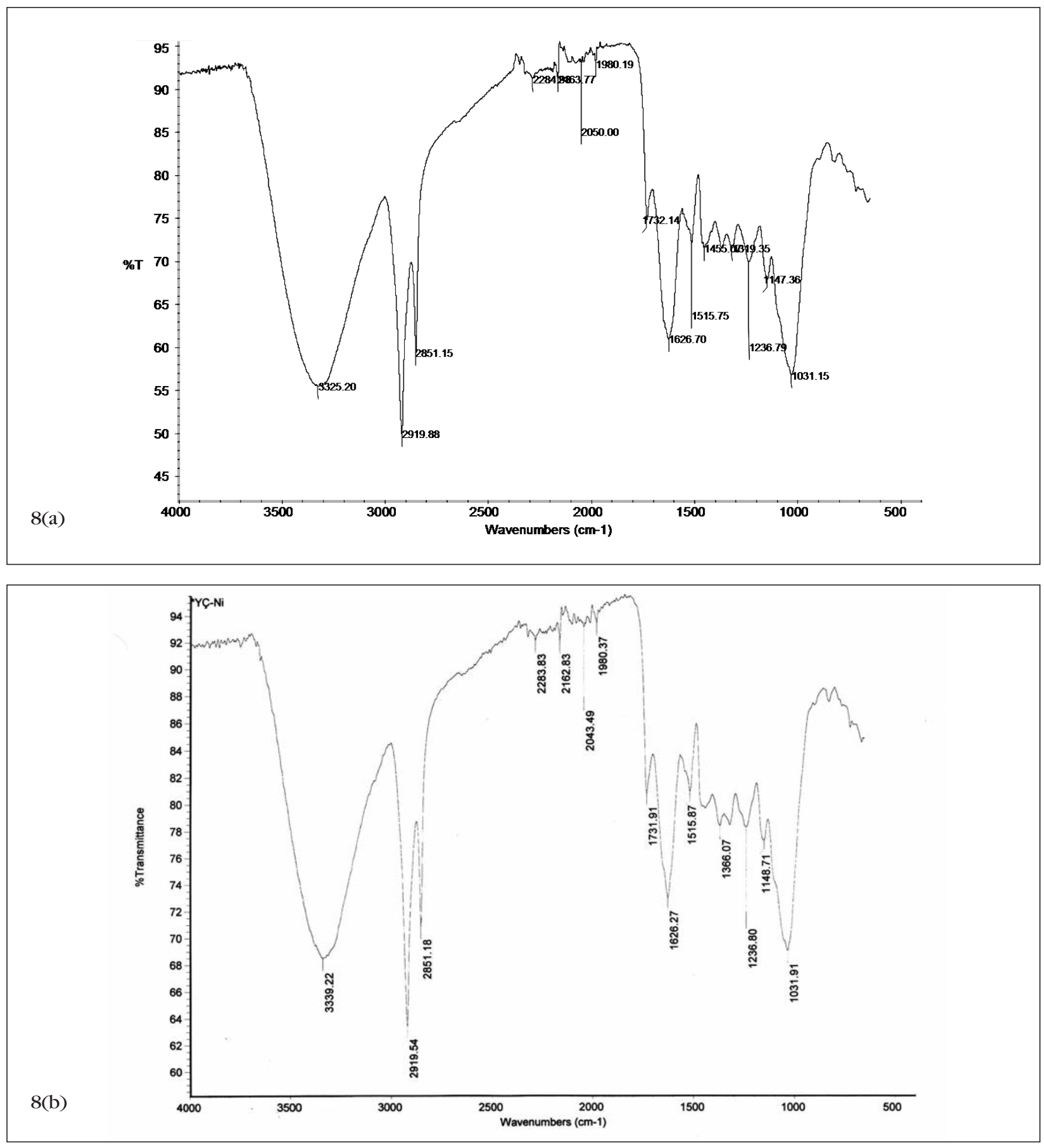

Fig. 8 ( $a$ and b). FTIR spectra of (a) tea waste and (b)-Ni loaded tea waste. 

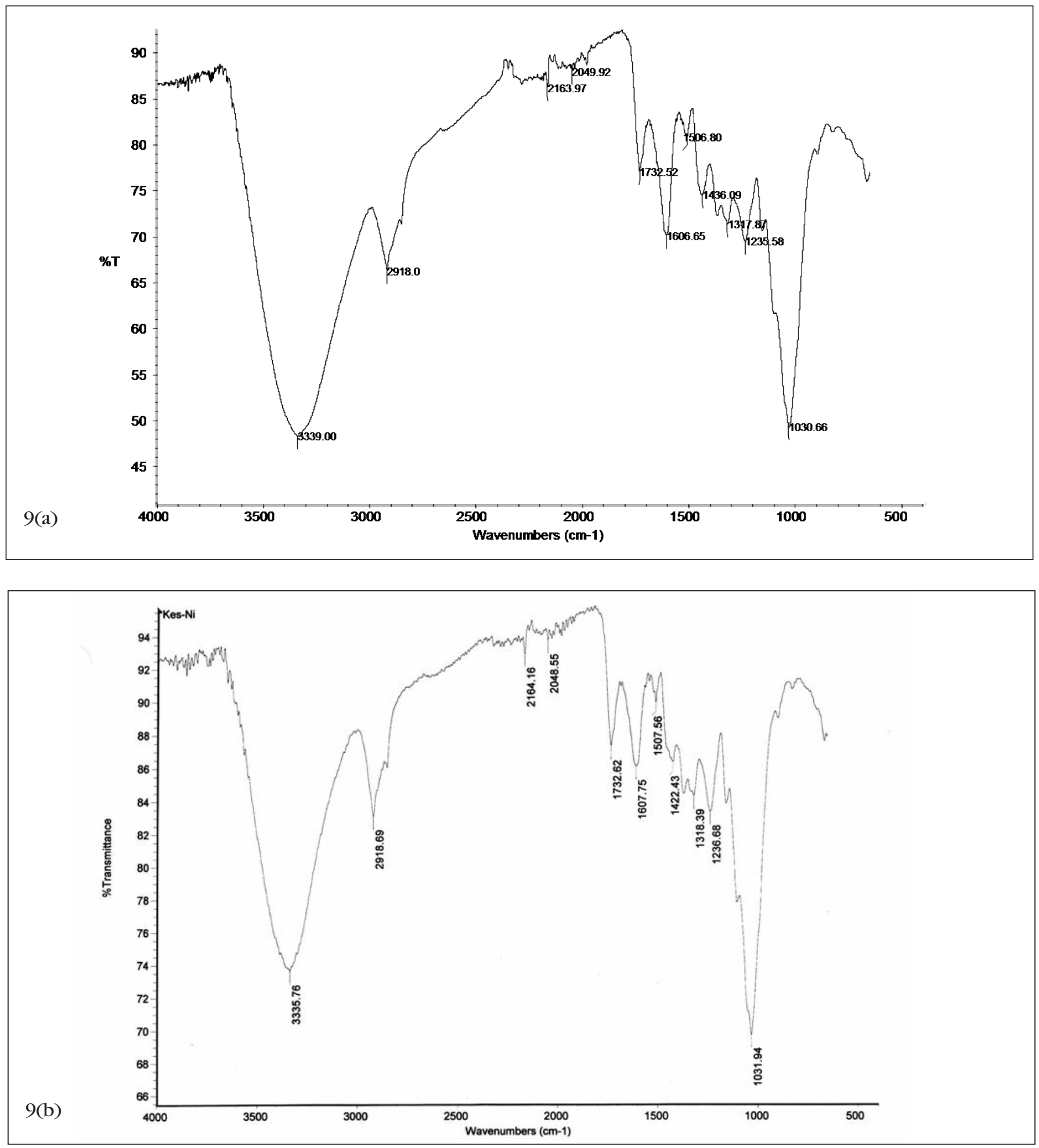

Fig. 9 ( $a$ and b). FTIR spectra of (a) chestnut shell and (b) Ni-loaded chestnut shell. 


\section{Atomic $_{\text {Spectroscopy }}^{\text {to }}$ \\ 1 Vol. 35(5), Sept./Oct. 2014}

\section{REFERENCES}

1. S. Kocaoba, Y. Orhan, and T. Akyüz, Desalination 214, 1 (2007).

2. K.G. Bhattacharyya, and S.S. Gupta, Adv. Colloid and Interface. 140, 114 (2008).

3. N. Pourreza, and K. Ghanemi, Spectrosc. Lett. 39. 127 (2006)

4. M.N.V. Prasad, and H. Freitas, Environ. Pollut. 110, 277 (2000).

5. G. Carrillo-Morales, M.M. DávilaJiménez, M.P. Elizalde-González, and A.A. Peláez-Cid, J. Chromatogr. A 938, 237 (2001).

6. P.M. Choksi, and V.Y. Joshi, Desalination 208, 216 (2007).

7. F.E. Okieimen, E.U. Okundia, and D.E. Ogbeifun, J. Chem. Technol. Biot. 51, 97 (1991)

8. I. Gaballah, and G. Kilbertus, J. Geochem. Explor. 62, 241 (1998).

9. S. Al-Asheh, and Z. Duvnjak, Sep. Sci. Technol. 33, 1303 (1998).

10. B.R. Reddy, N. Mirghaffari, and I. Gaballah, Resour. Conserv. Recy. 21, 227(1997).

11. G. Sun, and W. Shi, Ind. Eng. Chem. Res. 37, 1324 (1998).

12. V.K. Gupta, D. Mohan, S. Sharma, Sep. Sci. Technol. 33, 1331 (1998).

13. N. Khalid, P.O. Nilore, S. Ahmad, S.N. Kiani, and J. Ahmed, Sep. Sci. Technol. 33, 2349 (1998).

14. M. Ajmal, R.A. K. Rao, and B.A. Siddiqui, Water Res. 30, 1478 (1996).

15. C. Raji, and T.S. Anirudhan, Water Res. 32, 3772 (1998).

16. S. Baytak, and A.R. Türker, Clean Soil, Air, Water 37, 314 (2009).

17. M. Tuzen, M. Soylak, D. Citak, H.S. Ferreira, M.G.A. Korn, and M.A. Bezerra, J. Hazard. Mater., 162 (2009) 1041.

18. A.R. Türker, Clean - Soil, Air, Water 35, 548 (2007).

19. E. Malkoc, and Y. Nuhoglu, Sep. Purif. Technol. 54, 291 (2007).

20. N.V. Farinella, G.D. Matos, E.L. Lehmann, and M.A.Z. Arruda, J. Hazard. Mater. 154, 1007 (2008).
21. W.A. Carvalho, C. Vignado, and J. Fontana, J. Hazard. Mater. 153, 1240 (2008).

22. E. Malkoc, and Y. Nuhoglu, J. Hazard. Mater. 127, 120 (2005).

23. M. Jiang, X. Jin, X. Lu, and Z. Chen, Desalination 252, 33 (2010).

24. V.K. Gupta, M.R. Ganjali, A. Nayak, B. Bhushan, and S. Agarwal, Chem. Eng. J. 197, 330 (2012).

25. F.Y. Wang, H. Wang, and J.W. Ma, J. Hazard. Mater. 177, 300 (2010).

26. P.M. Choksi, and V.Y. Joshi, Desalination 208, 216 (2007).

27. J.Q. Albarelli, R.B. Rabelo, D.T. Santos, M.M. Beppu, and M.A.A Meireles, J. Supercrit. Fluid. 58, 343 (2011).

28. M.H. Kalavathy, and L.R. Miranda, Chem. Eng. J. 158, 188 (2010)

29. G. Vázquez, M.S. Freire, J. GonzálezAlvarez, and G. Antorrena, Desalination 249, 855 (2009).

30. U.K. Garg, M.P. Kaur, V.K. Garg, and D. Sud, Bioresource Technol. 99, 1325 (2008).

31. P. Djomgoue, M. Siewe, E. Djoufac, P. Kenfack, and D. Njopwouo, Appl. Surf. Sci. 258, 7470 (2012). 